\title{
Investigation of Cerium-Lithium Sealing Treatment of Cobalt-based Conversion Coatings Formed on Aluminum Alloys
}

\author{
Shubai LI ${ }^{1}$, Di MA ${ }^{2 *}$, Zhenzhen $\mathrm{XU}^{2}$, Pei YAO ${ }^{1}$, Yuan LIU ${ }^{1}$, Yutao SUN ${ }^{1}$ \\ ${ }^{1}$ Department of Chemical Engineering, Changzhou Institute of Engineering Technology, Changzhou 213000, China \\ ${ }^{2}$ School of Chemistry \& Environmental Engineering, Jiangsu University of Technology, Changzhou 213000, China \\ crossref http://dx.doi.org/10.5755/j01.ms.24.4.19132
}

Received 27 September 2017; accepted 13 January 2018

\begin{abstract}
A study was conducted to examine methods of adjusting cerium-lithium sealing process parameters in order to improve the corrosion protection capabilities of a cobalt-based chemical conversion film. In order to seal the pores of the cobaltbased conversion coatings, samples were treated in a cerium-lithium deposition bath in optimal process conditions. The optimal treatment condition was determined by examination of finished samples using the scanning electron microscope (SEM) and electrochemical test measurements. The corrosion behaviors of the sealing coatings were studied using an open circuit potential-time monitoring technique (OCPT), electrochemical impedance spectroscopy (EIS), and potentiodynamic polarization tests in $3.5 \mathrm{wt} . \% \mathrm{NaCl}$ solution. It was found that the best treatment process for the cobaltbased conversion coating was sealed in the cerium-lithium sealing solution for $2 \mathrm{~h}$ at $90{ }^{\circ} \mathrm{C}$.

Keywords: cerium, sealing treatment, aluminum alloy, corrosion resistance.
\end{abstract}

\section{INTRODUCTION}

Chromate treatments have superb corrosion resistance and have been the most commonly used technology for surface anti-corrosion pre-treatments. The technology had two major advantages: 1) Chromate treatment ensured that the metallic surfaces had a reliably tight protective film, and 2) The hexavalent chromium in the chromate film was partially soluble and was able to repair discontinuities in the film[1-4]. However, many countries have introduced strict rules and regulations on the use of hexavalent chromium ions [5-8] because hexavalent chromium ions can cause cancer in humans and improper handling can cause serious environmental pollution. Additionally, the wastewater treatment process is demanding.

Environmentally friendly alternatives to chromate treatments for protecting aluminum alloys have been investigated in the surface treatment field $[9,10]$. One area that has been researched extensively in recent years is the use of rare-earth salt conversion coatings for the corrosion protection of aluminum alloys [11-13]. Another alternative that has been widely studied is cerium compounds because they are non-toxic and relatively lowcost $[14,15]$. However, the surface oxide film is created by anodic oxidation or chemical oxidation of the porous structure and the film has poor corrosion resistance. The oxide film requires a sealing treatment to form cerium conversion coatings on the porous film of anodized aluminum [16 - 21].

There is an urgent need to develop chromium-free chemical oxidation technologies in order to produce reliable and effective aluminum alloy surface treatments because of the severe environmental contamination that is created during the conventional chromate chemical oxidation process[22, 23]. Ever since the first proposal for

\footnotetext{
* Corresponding author. Tel.: +86-15951207428.

E-mail address: madi@jsut.edu.cn (D. Ma)
}

preparing salt conversion films for aluminum alloy surfaces appeared [24], extensive research has been carried out around the world on the film forming mechanism and on the film forming processes for aluminum alloy rare earth conversion coatings [25]. Rare earth conversion coatings have proven to be ideal coatings for use as alternatives to chromate conversion coatings [26]. Although the cobalt salt conversion process was developed relatively earlier than other processes, it is considered a new technology in chromium-free conversion and has many advantages. And the approach already has been used for surface treatments in aerospace, electronics, and communications products [27 - 30].

Aluminum cobalt salt conversion technology was proposed for the first time by Schriever, working for Boeing [31]. The main components of the conversion fluid in this method, were cobalt salt (trivalent cobalt valence stabilizer), ligand, and an accelerator agent. The use of the ligand is a key factor in this method, as it can affect the life and cost of the cobalt salt conversion coating. Earlier, $\mathrm{NH}_{3}$ was the ligand of choice, but more recently anionic ligands such as $\mathrm{NO}_{2}^{-}, \mathrm{CH}_{3} \mathrm{COO}^{-}$, and $\mathrm{HCOO}^{-}$have been used.

Nevertheless, improvements need to be made to the corrosion resistance of cerium-based sealing of porous film. In consequence, researchers have been studying ceriumbased sealing of cobalt-based conversion coatings. The purpose of the present investigation was to examine methods for changing the sealing process parameters in order to improve the corrosion protection of cobalt-based chemical conversion films.

\section{EXPERIMENTAL}

Coupons of 1020 pure aluminum sheet, $100 \mathrm{~mm} \times 30 \mathrm{~mm} \times 0.5 \mathrm{~mm}$, were used as the substrate for the cobalt-based conversion coating process. The specimens were cleaned with ethanol and polished with $1.5 \mathrm{~mol} / \mathrm{L} \mathrm{NaOH} . \mathrm{HNO}_{3}$ were used to adjust the $\mathrm{pH}$ to the 
required value and the solution was kept at a desired temperature. The pre-treated aluminum sheet was put into the solution of $20 \mathrm{~g} / \mathrm{L} \mathrm{NaNO}_{2}, 30 \mathrm{~g} / \mathrm{L} \mathrm{Co}\left(\mathrm{NO}_{3}\right)_{2} \cdot 6 \mathrm{H}_{2} \mathrm{O}$ and $20 \mathrm{~g} / \mathrm{L} \mathrm{NaClO}_{3}$ to form conversion coatings on aluminum surfaces. Three different test parameters based on $\mathrm{Ce}\left(\mathrm{NO}_{3}\right)_{3}$ and $\mathrm{LiNO}_{3}$ were performed by immersing the cobalt-based conversion coating under the conditions described. Scanning electron microscopy (SEM) was used to study the morphology of the cobalt-based conversion coating that had been formed by the above procedure. The apparatus used was a Hitachi S-3400NII SEM working at $15 \mathrm{KV}$.

A three-electrode test configuration was used for the electrochemical experiments. A working electrode area $(1 \mathrm{~cm} \times 1 \mathrm{~cm})$ was retained on the aluminum samples. The reference electrode was a saturated calomel electrode (SCE) and the counting electrode was a platinum electrode. The test solution was $0.5 \mathrm{wt} \% \mathrm{NaCl}$ solution. A CHI660C type Electrochemical Analyzer/Workstation was used to record electrochemical measurements at the open circuit potential. The scan time was $400 \mathrm{~s}$, the sampling interval was $0.1 \mathrm{~s}$, the high potential was limited to $1 \mathrm{~V}$ and the low potential was limited to $-1 \mathrm{~V}$. The electrochemical impedance measurements were conducted at the open circuit potential, the high frequency was $100 \mathrm{kHz}$, the low frequency was $0.1 \mathrm{~Hz}$, and the applied perturbation amplitude was $0.01 \mathrm{~V}$. The standing time was $60 \mathrm{~s}$, and the instrument was operated in autoranging mode. In Tafel curve measurements, the scanning speed was $0.5 \mathrm{mV} / \mathrm{s}$, and the sensitivity was automatically adjusted to avoid over flow.

\subsection{SEM morphological analyses}

The rare earth conversion coating from cobalt salts was prepared on a pure aluminum surface. This coating was colorless and transparent to the naked eye. The morphology of the samples was examined using the SEM in order to gain a better understanding of the structure of the cobalt salt conversion coating on the aluminum alloy sealed by $\mathrm{Ce}\left(\mathrm{NO}_{3}\right)_{3}$ and $\mathrm{LiNO}_{3}$ at different temperatures. In the film formation process, the reaction produces gas that causes cracks in the surface of the film. Subsequent different conditions in closed treatment conditions make the cracks smaller or they may even disappear. When the samples were sealed within the temperature range of $20-60^{\circ} \mathrm{C}$, the surfaces of the coatings had many voids and some cracks (Fig. $1 \mathrm{a}$ and c) and these were most pronounced for the sealing treatment at $60{ }^{\circ} \mathrm{C}$. When the samples were sealed at $40{ }^{\circ} \mathrm{C}$, the surface of the coating was smooth, and a number of small pores were observed on the surface (Fig. $1 \mathrm{~b}$ ). The sealing treatment effects were lessened because the coating was relatively loose. The cracks and pores showed that the lower temperature of the sealing treatment was not able to close completely the pores on the coating surface; i.e. the sealing treatment was not completely effective when the samples were sealed at $40{ }^{\circ} \mathrm{C}$ (Fig. 1 b). No pores were observed at 80 and $100{ }^{\circ} \mathrm{C}$ (Fig. $1 \mathrm{~d}$ and e). However, there were some fine cracks in the surface. The film surface consisted of uniformly distributed pores, which can be seen in the SEM observation chart (Fig. 1 f).

\section{RESULTS AND ANALYSIS}

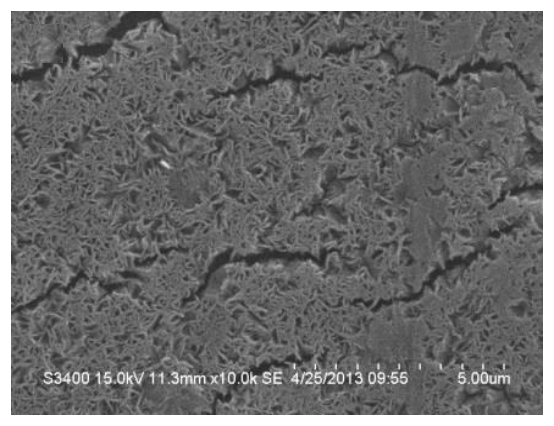

$\mathrm{a}$

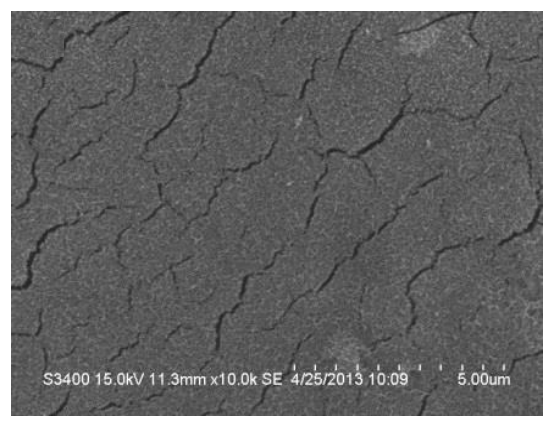

d

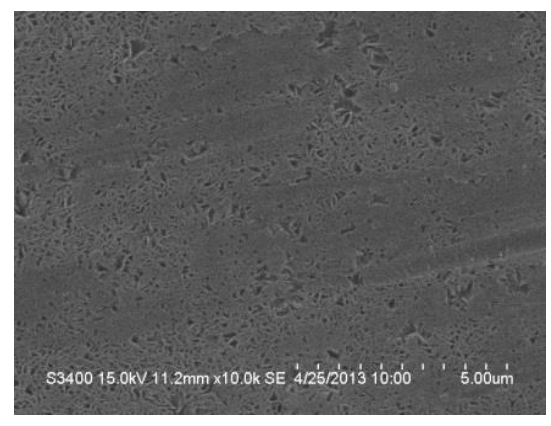

b

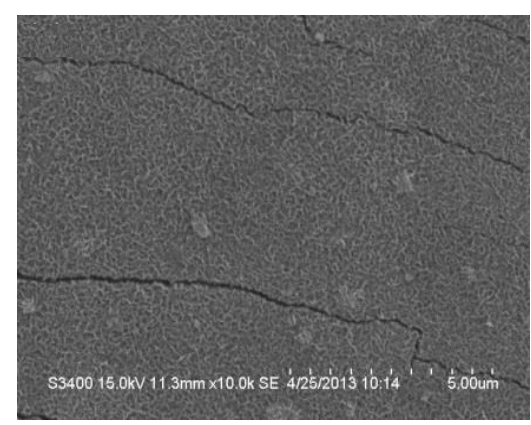

e

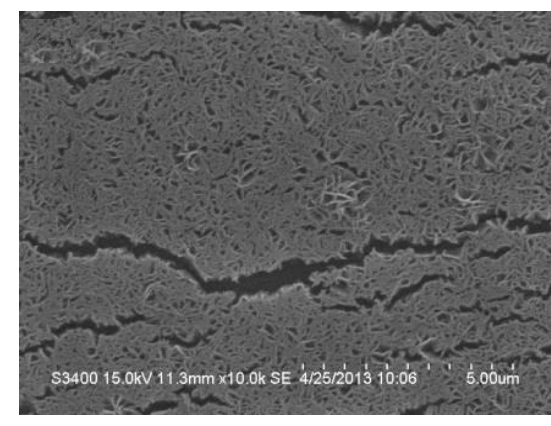

c

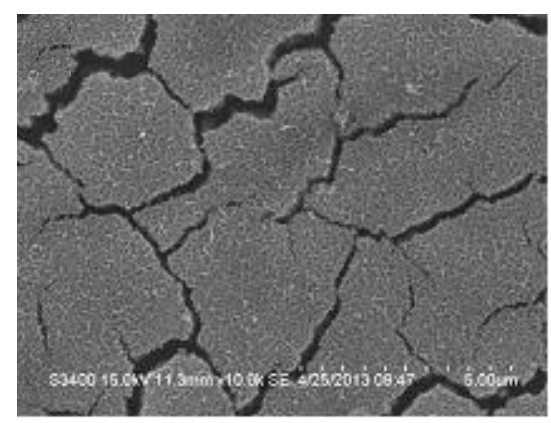

f

Fig. 1. SEM micrographs showing the morphology of sealing treatment at: $\mathrm{a}-20{ }^{\circ} \mathrm{C} ; \mathrm{b}-40{ }^{\circ} \mathrm{C} ; \mathrm{c}-60{ }^{\circ} \mathrm{C} ; \mathrm{d}-80{ }^{\circ} \mathrm{C} ; \mathrm{e}-100{ }^{\circ} \mathrm{C}$; $\mathrm{f}$-cobalt chemical conversion coating on pure aluminum 
In summary, when the temperature was increased from 60 to $100{ }^{\circ} \mathrm{C}$ (Fig. $1 \mathrm{c}, \mathrm{d}$ and e), the effects of the sealing treatment were improved, as evidenced by the SEM results. After applying the sealing treatment, the crack width on the film surface became smaller, but the cracks were not removed completely.

\subsection{Oxidation-protective properties of the coating}

The electrochemical measurements were conducted at the stabilized open circuit potential. Plots of the open circuit potential time monitoring (OCPT) curves for different sealing coatings at different temperatures and sealing times concentration of the $\mathrm{LiNO}_{3}$ sealing treatment are shown in Fig. 2. From the OCPT curves for the sealing coatings performed at different temperatures while keeping constant the sealing time and the solution concentration (Fig. 2 a). The values of the steady state open circuit potential $\left(\mathrm{E}_{\mathrm{OC}}\right)$ for these three electrodes were between -1.05 and $-1.15 \mathrm{~V}$. The sealing coating that was prepared at $40{ }^{\circ} \mathrm{C}$ showed a lower $\mathrm{E}_{\mathrm{OC}}$, possibly because the pores of the coating were not closed during the sealing treatment. The OCPT curves were used to determine the temperature that would provide the best sealing treatment. When the sealing treatment was at $100^{\circ} \mathrm{C}$, the $\mathrm{E}_{\mathrm{OC}}$ was the largest and the sealing coating had an optimal corrosion protection performance. However, after an initial potential decay, the electrode sealed at $60{ }^{\circ} \mathrm{C}$. This potential decay was associated with a change in the surface morphology, as revealed by SEM. The unsealed pores of the sealing coating surface caused poor corrosion resistance in the electrode so that the $\mathrm{E}_{\mathrm{OC}}$ was lower than when the sealing treatment was at a higher temperature. The changing trends of the OCPT curves (Fig. 2 b) show that, with the sealing time enhanced the corrosion resistance of the conversion coatings and the $E_{O C}$ of the electrodes that were sealed for $1.5 \mathrm{~h}$ was highest when the potential trend changed. When $\mathrm{LiNO}_{3}$ was added to the sealing solution, the potential trace tended to flatten at about $250 \mathrm{~s}$ (Fig. $2 \mathrm{c}$ ). This was because lithium oxide in the sealing coating exhibits selfhealing properties. When the potential reached equilibrium, the $\mathrm{E}_{\mathrm{OC}}$ of the electrodes was highest for those samples that were sealed with $5 \mathrm{~g} / \mathrm{L} \mathrm{LiNO}_{3}$ added to the sealing solution. If the proportion of $\mathrm{LiNO}_{3}$ increased beyond this concentration the sealed coatings had poorer corrosion resistance. Through analyzing the OCPT curves it was found that the optimum process for the treatment of the sealing coat was $1.5 \mathrm{~h}$ at $100{ }^{\circ} \mathrm{C}$ with $5 \mathrm{~g} / \mathrm{L} \mathrm{LiNO}_{3}$ added to the cerium sealing solution.

EIS measurements were performed in $3.5 \mathrm{wt} \% \mathrm{NaCl}$ solution at the $\mathrm{E}_{\mathrm{OC}}$ in order to investigate the influence of the sealing treatment as a function of the differences in the corrosion resistance of the cobalt-based conversion coatings. The impedance spectra recorded all the Nyquist curves in the low-frequency range when coating sealing was performed at different temperatures, sealing times, and concentrations of $\mathrm{LiNO}_{3}$ (Fig. 3). The EIS data were analyzed using Nova software (issued by Metrohm Autolab). The corrosion resistances of the sealing coatings were characterized by the radius size of semi-circular arc curves at lower frequencies. Larger radiuses of the Nyquist curves were associated with greater resistances (indicative of lower corrosion rate), and therefore higher corrosion resistance of the sealed coatings. With the increase of temperature, arc diameter was basically on the rise. This showed that the increase of temperature increased corrosion resistance of the sample surface. Better corrosion resistance of the electrodes was obtained using a sealing treatment at $80-100{ }^{\circ} \mathrm{C}$. The diameter of the main Nyquist arc increased, and the corrosion resistance of the sealing coatings was better when the sealing time was extended (Fig. 3b). However, as the addition of $\mathrm{LiNO}_{3}$ to the cerium sealing solutions gradually was increased, the diameters of the Nyquist arcs became smaller (Fig. $3 \mathrm{c}$ ). When the sealing solution had a certain cerium quality, $5 \mathrm{~g} / \mathrm{L} \mathrm{LiNO}_{3}$ could improve the corrosion resistance of the sealed coating.

The polarization curves of the sealing coatings (for sealing treatments performed at different temperatures, sealing times, and concentrations of $\mathrm{LiNO}_{3}$ in the cerium sealing solution) are shown in Fig. 4. The values of the corrosion current density and corrosion potential can be obtained from the potentiodynamic polarization curves via Tafel region extrapolation. As can be observed from the plots, there was a significant difference in the polarization response when the sealing condition was changed because the porous morphology of conversion coatings was not completely closed when the samples were sealed under different sealing conditions.

In addition, the sealing coating with high corrosion potential had the highest corrosion resistance.

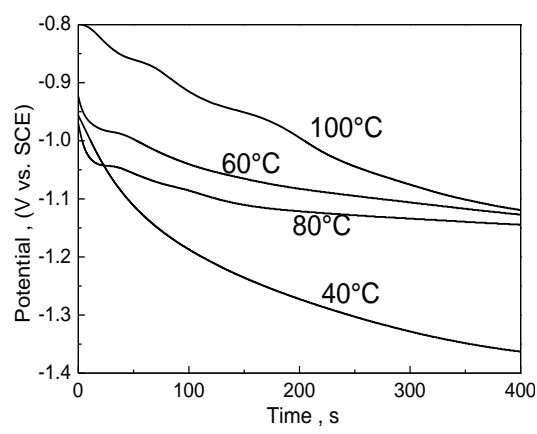

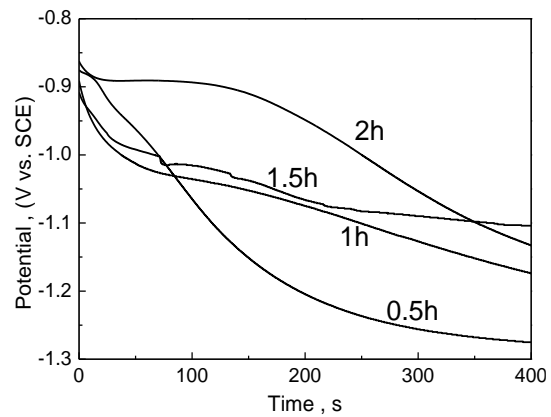

$\mathrm{b}$

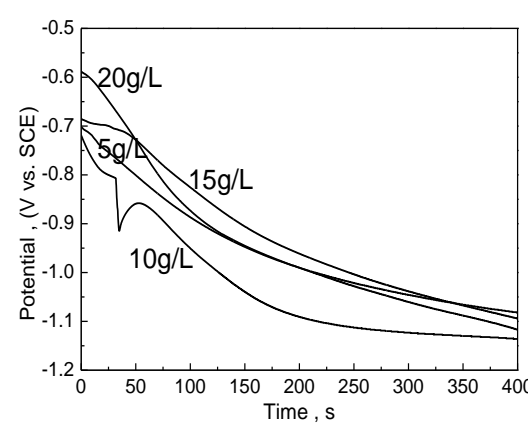

$\mathrm{c}$

Fig. 2. a-experimental OCPT curves for the sealing treatment at $40,60,80$ and $100^{\circ} \mathrm{C} ; \mathrm{b}$-sealing treatment for $0.5 \mathrm{~h}, 1 \mathrm{~h}, 1.5 \mathrm{~h}$ and $2 \mathrm{~h} ; \mathrm{c}-$ sealing treatment in solutions with different $\mathrm{LiNO}_{3}$ concentrations 


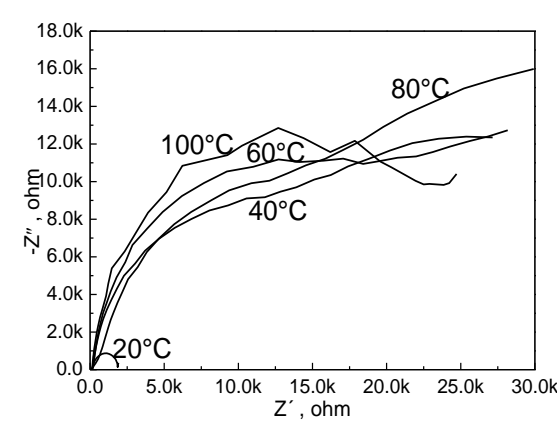

a

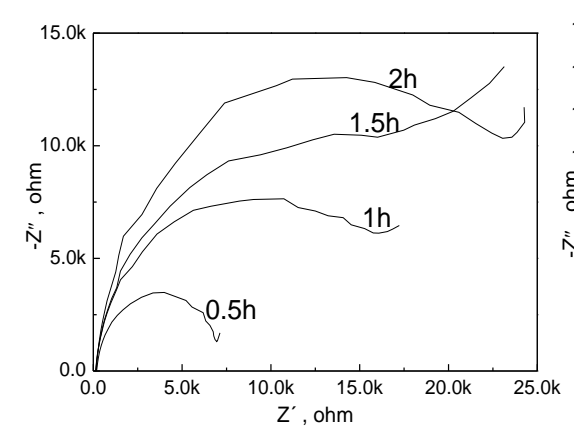

b

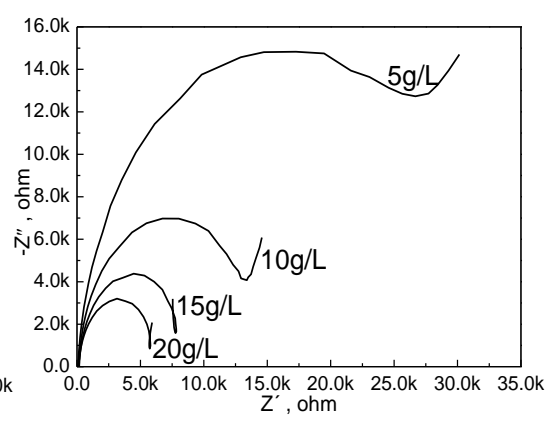

c

Fig. 3. a-experimental Nyquist curves for sealing treatment at $20,40,60,80$ and $100^{\circ} \mathrm{C}$; b-sealing treatment for $0.5 \mathrm{~h}, 1 \mathrm{~h}, 1.5 \mathrm{~h}$ and $2 \mathrm{~h} ; \mathrm{c}-$-sealing treatment in different concentrations of $\mathrm{LiNO}_{3}$

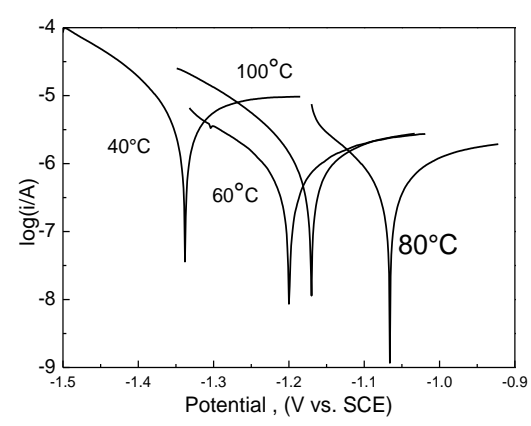

a

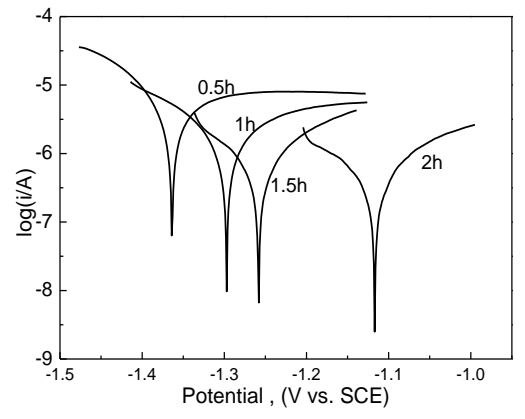

b

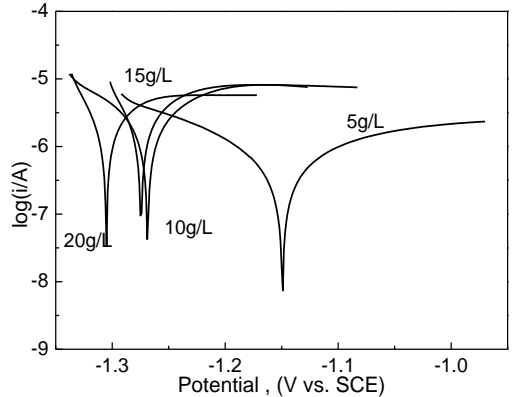

$\mathrm{c}$

Fig. 4. a-polarization curves in $3.5 \mathrm{wt} . \% \mathrm{NaCl}$ of sealing treatment at $40,60,80$ and $100^{\circ} \mathrm{C}$; $\mathrm{b}$-sealing treatment for $0.5 \mathrm{~h}, 1 \mathrm{~h}, 1.5 \mathrm{~h}$ and $2 \mathrm{~h} ; \mathrm{c}-$ sealing treatment with different concentrations of $\mathrm{LiNO}_{3}$

As can be seen in Fig. 4 a, the electrode that was sealed in a cerium sealing solution at $80^{\circ} \mathrm{C}$ had a higher corrosion potential $(-1.066 \mathrm{~V})$ than the electrodes sealed at the other temperatures.

The order of the corrosion potentials was consistent with the AC impedance results. When the processing time of the sealing treatment was extended, the corrosion potential increased (Fig. 4 b). The highest corrosion potential was $-1.117 \mathrm{~V}$, which was achieved when the samples were treated in the cerium and lithium bath for $2 \mathrm{~h}$. The sealing time determined the degree of sealing of the pores in the conversion coatings. Fig. $4 \mathrm{c}$ illustrates the effect of the concentration of $\mathrm{LiNO}_{3}$ on the degree of sealing. It can be observed that the electrochemical behavior of the sealing treatment did not exhibit a difference for concentrations of $\mathrm{LiNO}_{3}$ at 10 and $20 \mathrm{~g} / \mathrm{L}$. The corrosion potential of the sample that was treated with $5 \mathrm{~g} / \mathrm{L} \mathrm{LiNO}_{3}$ cerium sealing solution was higher than for other concentrations. It was observed that the corrosion resistance was better than for samples that had been treated with a sealing treatment concentration of $5 \mathrm{~g} / \mathrm{L}$. The film obtained using the above-mentioned parameters had excellent corrosion resistance and could be widely used in the surface treatment industry to increase the service life of the aluminum substrates. The electrochemical tests demonstrated that the film formed under the prescribed conditions did so by the following reactions [32]:

$$
\begin{aligned}
& \mathrm{Al}+3 \mathrm{Co}[\mathrm{R}]_{6}^{3+} \longrightarrow \mathrm{Al}^{3+}+3 \mathrm{Co}^{2+} ; \\
& 2 \mathrm{Al}^{3+}+4 \mathrm{H}_{2} \mathrm{O} \longrightarrow 2 \mathrm{AlO}(\mathrm{OH})+6 \mathrm{H}^{+} ;
\end{aligned}
$$

$$
\mathrm{Co}^{3+}+2 \mathrm{H}_{2} \mathrm{O}^{+} \longrightarrow \mathrm{CoO}(\mathrm{OH})+3 \mathrm{H}^{+}
$$

\section{CONCLUSIONS}

The pores of cobalt-based conversion coatings were successfully sealed by means of deposition in a ceriumlithium bath in optimal process conditions. SEM micrographs showed that the sealing treatments completely covered the pores of the optimal cobalt-based conversion coatings when the sealing temperatures were greater than $80^{\circ} \mathrm{C}$, but the larger cracks in the coating surface that were sealed at $80-100{ }^{\circ} \mathrm{C}$ indicated that the coating was defective. The OCPT curves showed that the sealing process was best when the treatment was sealed for $1.5 \mathrm{~h}$ at $100^{\circ} \mathrm{C}$ and with $5 \mathrm{~g} / \mathrm{L} \mathrm{LiNO}_{3}$ added into the cerium sealing solution. The Nyquist curves showed that the sealing process was the best when the reaction time was $2 \mathrm{~h}$, the sealing temperature was $80-100^{\circ} \mathrm{C}$, and $5 \mathrm{~g} / \mathrm{L} \mathrm{LiNO}_{3}$ was added to the cerium sealing solution. The polarization curves showed that the sealing process was best when the reaction time was $2 \mathrm{~h}$ at $80^{\circ} \mathrm{C}$ with $5 \mathrm{~g} / \mathrm{L} \mathrm{LiNO}_{3}$ added the cerium sealing solution. In summary, the best treatment process for the cobalt-based conversion coating was obtained in a sealed cerium-lithium bath for $2 \mathrm{~h}$ at $90^{\circ} \mathrm{C}$, and the $\mathrm{LiNO}_{3}$ concentration of the cerium-lithium sealing solution was $5 \mathrm{~g} / \mathrm{L}$.

\section{Acknowledgments}

This work was sponsored by Qing-Lan Project, the Natural Science Foundation of the Jiangsu Higher Education Institutions (No.17KJA610002 and 
No.16KJB530005), Jiangsu Key Research and Social Development Project (No. BE2017649), Jiangsu Overseas Research \& Training Program for University Prominent Young \& Middle-aged Teachers and Presidents, and Topnotch Academic Programs Project of Jiangsu Higher Education Institutions and Colleges (TAPP:PPZY2015B178).

\section{REFERENCES}

1. Cui, X.J., Liu, C.H., $\quad$ Yang, R.S., $\quad$ Li, M.T., Lin, X.Z., Gong, M. Phosphate Film Free of Chromate, Fluoride and Nitrite on AZ31 Magnesium Alloy and Its Corrosion resistance Transactions of Nonferrous Metals Society of China 22 (11) 2012: pp. 2713-2718. https://doi.org/10.1016/S1003-6326(11)61522-7

2. Indumathi, S.N.I., $\quad$ Vasudevan, T., Sundarrajan, S., Subba Rao, B.V., $\quad$ Murthy, C.V.S., $\quad$ Yadav, D.R. Cadmium- and Chromate-free Coating Schemes for Corrosion Protection of 15CDV6 Steel Metal Finishing 1093 2011: pp. 15-21. https://doi.org/10.1016/S0026-0576(11)00010-9

3. Bierwagen, G., Brown, R., Battocchi, D., Hayes, $\mathbf{S}$. Active Metal-based Corrosion Protective Coating Systems for Aircraft Requiring No-chromate Pretreatment Progress in Organic Coatings 67 (2) 2010: pp. 195-208. https://doi.org/10.1016/j.porgcoat.2009.10.009

4. Bhargava, G., Allen, F. Self-Healing, Chromate-free Conversion Coating for Magnesium Alloys Metal Finishing 110 (4) 2012: pp. $32-38$. https://doi.org/10.1016/j.surfcoat.2015.02.049

5. Chidambaram, D., Clayton, C.R., Halada, G.P. The Role of Hexafluorozirconate in the Formation of Chromate Conversion Coatings on Aluminum Alloys Electrochimica Acta 51 (14) 2006: pp. 2862-2871. https://doi.org/10.1016/j.electacta.2005.08.022

6. Campestrini, P., van Westing, E.P.M., de Wit, J.H.W. Influence of Surface Preparation on Performance of Chromate Conversion Coatings on Alclad 2024 Aluminium Alloy: Part I: Nucleation and Growth Electrochimica Acta 46 (16) 2001: pp. 2553-2571. https://doi.org/10.1016/S0013-4686(01)00476-5

7. Liu, Y., Skeldon, P., Thompson, G.E., Habazaki, H., Shimizu, K. Chromate Conversion Coatings on Aluminium-copper Alloys Corrosion Science 47 (2) 2005: pp. $341-354$.

https://doi.org/10.1016/j.corsci.2004.06.005

8. Liu, Y., Skeldon, P., Thompson, G.E., Habazaki, H., Shimizu, K. Chromate Conversion Coatings on Aluminium: Influences of Alloying Corrosion Science 46 (2) 2004: pp. 297-312.

https://doi.org/10.1016/S0010-938X(03)00157-4

9. Twite, R.L., Bierwagen, G.P. Review of Alternatives to Chromate for Corrosion Protection of Aluminum Aerospace Alloys Progress in Organic Coatings $33(2)$ 1998: pp. $91-100$. https://doi.org/10.1016/S0300-9440(98)00015-0

10. Kamaraj, K., $\quad$ Karpakam, V., $\quad$ Syed Azim, S., Sathiyanarayanan, S. Electropolymerised Polyaniline Films as Effective Replacement of Carcinogenic Chromate Treatments for Corrosion Protection of Aluminium Alloys Synthetic Metals 162 (5-6) 2012: pp. 536-542. https://doi.org/10.1016/j.synthmet.2012.01.022

11. Xingwen, Y., Chunan, C., Zhiming, Y., Derui, Z., Zhongda, Y. Study of Double Layer Rare Earth Metal
Conversion Coating on Aluminum Alloy LY12 Corrosion Science 43 (7) 2001: pp. 1283-1294.

https://doi.org/10.1016/S0010-938X(00)00141-4

12. Han, Z., Zuo, Y., Ju, P., Tang, Y., Zhao, X., Tang, J. The Preparation and Characteristics of a Rare Earth/nano- $\mathrm{TiO}_{2}$ Composite Coating on Aluminum Alloy by Brush Plating Surface and Coatings Technology 206 (14) 2012: pp. $3264-3269$. https://doi.org/10.1016/j.surfcoat.2012.01.027

13. Hamdy, A.S., Butt, D.P. Corrosion Mitigation of Rareearth Metals Containing Magnesium EV31A-T6 Alloy Via Chrome-free Conversion Coating Treatment Electrochimica Acta 108 2013: pp. 852-859.

https://doi.org/10.1016/j.electacta.2013.07.043

14. Zhao, D., Sun, J., Zhang, L., Tan, Y., Li, J. Corrosion Behavior of Rare Earth Cerium Based Conversion Coating on Aluminum Alloy Journal of Rare Earths 28 Supplement 1 (0) 2010: pp. 371-374. https://doi.org/10.1016/S1002-0721(10)60338-9

15. O'Keefe, M.J., Geng, S., Joshi, S. Cerium-based Conversion Coatings as Alternatives to Hex Chrome: Rareearth Compounds Provide Resistance Against Corrosion for Aluminum Alloys in Military Applications Metal Finishing 105 (5) 2007: pp. 25-28. https://doi.org/10.1016/S0026-0576(07)80547-2

16. Yu, X., Yan, C., Cao, C. Study on the Rare Earth Sealing Procedure of the Porous Film of Anodized Al6061/SiCp Materials Chemistry and Physics $76(3)$ 2002: pp. $228-235$. https://doi.org/10.1016/S0254-0584(01)00536-3

17. Laleh, M., Kargar, F., Rouhaghdam, A.S. Investigation of Rare Earth Sealing of Porous Micro-arc Oxidation Coating Formed on AZ91D Magnesium Alloy Journal of Rare Earths 30 (12) 2012: pp. 1293-1297. https://doi.org/10.1016/S1002-0721(12)60223-3

18. Hu, N., Dong, X., He, X., Browning, J.F., Schaefer, D.W. Effect of Sealing on the Morphology of Anodized Aluminum Oxide Corrosion Science $97(0)$ 2015: pp. 17-24. https://doi.org/10.1016/j.corsci.2015.03.021

19. Pardo, A., Merino, M.C., Arrabal, R., Merino, S., Viejo, F., Carboneras, M. Effect of Ce Surface Treatments on Corrosion Resistance of A3xx.x/SiCp Composites in Salt Fog Surface and Coatings Technology 200 (9) 2006: pp. $2938-2947$.

https://doi.org/10.1016/j.surfcoat.2005.05.028

20. Lee, J., Kim, Y., Jang, H., Chung, W. $\mathrm{Cr}_{2} \mathrm{O}_{3}$ Sealing of Anodized Aluminum Alloy by Heat Treatment Surface and Coatings Technology 243 (0) 2014: pp. 34-38. https://doi.org/10.1016/j.surfcoat.2012.05.071

21. Mohedano, M., Blawert, C., Zheludkevich, M.L. Cerium-based Sealing of PEO Coated AM50 Magnesium Alloy Surface and Coatings Technology $269(0)$ 2015: pp. $145-154$.

https://doi.org/10.1016/j.surfcoat.2015.01.003

22. Heller, D.K., Fahrenholtz, W.G., O'Keefe, M.J. Effect of Phosphate Source on Post-Treatment of Cerium-Based Conversion Coatings on Al 2024-T3 Journal of E; lectrochemial Society 156 (11) 2009: pp. C400-C406. https://doi.org/10.1149/1.3224005

23. Pinc, W., Yu, P., O'Keefe, M., Fahrenholtz, W. Effect of Gelatin Additions on the Corrosion Resistance of Cerium Based Conversion Coatings Spray Deposited on Al 2024T3 Surface and Coatings Technology 203 (23) 2009: pp. $3533-3540$. 
https://doi.org/10.1016/j.surfcoat.2009.05.019

24. Hinton, B. R. W., Arnott, D. R., Ryan, N. E., "Inhibition of Aluminum Alloy Corrosion by Cerous Cations", Metals Forum, 7, (4), 1984: pp. 211-217.

25. Renshaw, J.T. Aluminum Pretreatment: Next Generation Non-chrome Technologies are Ready for the New Millennium Metal Finishing 95 (12) 1997: pp. 28-31. https://doi.org/10.1016/S0026-0576(97)82644-X

26. Cai, J., Cao, F., Chang, L., Zheng, J., Zhang, J., Cao, C. The Preparation and Corrosion Behaviors of MAO Coating on AZ91D with Rare Earth Conversion Precursor Film Applied Surface Science 257 (8) 2011: pp. 3804-3811. https://doi.org/10.1016/j.apsusc.2010.11.153

27. Yang, X., Wang, G., Dong, G., Gong, F., Zhang, M. Rare Earth Conversion Coating on $\mathrm{Mg}-8.5 \mathrm{Li}$ Alloys Journal of Alloys and Compounds $487(1-2)$ 2009: pp. 64-68. https://doi.org/10.1016/j.jallcom.2009.07.113

28. Wei-Kun, C., Ching-Yuan, B. The Effect of Chromic Sulfate Concentration and Immersion Time on the Structures and Anticorrosive Performance of the $\mathrm{Cr}(\mathrm{III})$
Conversion Coatings on Aluminum Alloys Surface Science 1 (16) 2010: pp. 4924-4929. https://doi.org/10.1016/j.apsusc.2010.03.003

29. Zuo, X., Li, W., Mu, S., Du, J., Yang, Y., Tang, P. Investigation of Composition and Structure for a Novel $\mathrm{Ti}-\mathrm{Zr}$ Chemical Conversion Coating on 6063 Aluminum Alloy Progress in Organic Coatings 87 2015: pp. $61-68$. https://doi.org/10.1016/j.porgcoat.2015.05.008

30. Santa Coloma, P., $\quad$ Izagirre, U., $\quad$ Belaustegi, Y., Jorcin, J.B., Cano, F.J., Lapeña, N. Chromium-free Conversion Coatings Based on Inorganic Salts $(\mathrm{Zr} / \mathrm{Ti} / \mathrm{Mn} / \mathrm{Mo})$ for Aluminum Alloys Used in Aircraft Applications Applied Surface Science 345 2015: pp. $24-35$. https://doi.org/10.1016/j.apsusc.2015.02.179

31. Schriever. Non-chromated Oxide Coating for Aluminum Substrates, Patent US 5298092, 1993.

32. Schriever. Non-chromated Oxide Coating for Aluminum Substrates, Patent US 5468307, 1995. 